\title{
Voluntary work of pharmacy students in two regions of South Korea without the separation of the dispensary from medical practice
}

\author{
Young-Mo Yang ${ }^{1}$, Eun Jeong ${ }^{2}$ and Eun Joo Choi ${ }^{1}$ \\ 1'Department of Pharmacy, College of Pharmacy, Chosun University, 309 Pilmun-daero, Dong-gu, Gwangju, SOUTH KOREA. \\ ${ }^{2}$ Department of Food and Nutrition, Chosun University, 309 Pilmun-daero, Dong-gu, Gwangju, SOUTH KOREA.
}

\begin{abstract}
Background: Participation in a medical volunteer work positively affects some of the beliefs and perceptions of pharmacy students. However, the volunteer activities by pharmacy students have been rarely performed and studied in Korea. The objectives of this study were to introduce the volunteer activities by pharmacists and pharmacy students at the medically underserved regions without separation of prescribing and dispensing in Korea and to determine health conditions and prevalence and management of chronic diseases (CDs) in the residents of these regions. Methods: Survey instruments consisting of 23 questions were administered to the residents who visited the temporary pharmacy during the volunteer services. Results: A total of 352 residents completed the survey, and $66.3 \%$ of residents were over 70 years old. More than $12 \%$ of residents responded that their health conditions were good, and $76.5 \%$ of residents had at least $1 \mathrm{CD}$. Over $73 \%$ of residents responded that they took all doses of medications prescribed while $5.7 \%$ of residents answered that they missed all those of them. Conclusions: Through the volunteer activities, pharmacists and pharmacy students will play a meaningful role in providing a medical care in order to effectively manage CDs at the medically underserved areas in Korea.
\end{abstract}

Key words: Volunteer works, Korean pharmacy students, Medically underserved areas, Advanced pharmacy practice experience.

\section{INTRODUCTION}

Under the old health care system in Korea, pharmacists could write prescriptions while doctors could freely dispense medications to patients, which resulted in patients unintentionally abusing and misusing prescribed drugs, especially antibotics. ${ }^{1}$ This led the Korean government to implement the Korean Health Care System Reform Act of 2000 (KHCSRA 2000) called the Separation of Prescribing and Dispensing. ${ }^{1}$ The aims of this reform were to fundamentally alter the inefficient Korean health delivery system, to reduce prescription drug abuse and misuse by patients, and to lower health care costs by reducing unnecessary pharmaceutical expenditure. ${ }^{2}$ Since 1 July 2000 , pharmacists in Korea have been prohibited from prescribing medications, and doctors have not been able to dispense drugs anymore. ${ }^{1}$ In other words, patients have to purchase prescription medications from pharmacies with prescriptions written by their doctors.

However, there are still regions in Korea where the separation of prescribing and dispensing has not been applied. Approximately $90 \%$ of these regions are located in rural areas where there are not enough hospitals and pharmacies to provide health
Submission Date : 18-04-2016 Revision Date : 20-06-2016 Accepted Date :13-07-2016 DOI: 10.5530/ijper.50.3.6 Correspondence: Eun Joo Choi, PharmD, PhD

Department of Pharmacy, College of Pharmacy, Chosun University, 309 Pilmun-daero, Dong-gu, Gwangju 61452, South Korea.

Telephone: +82 622306382

Fax: +82 622225414

E-mail: ejchoi@chosun.ac.kr

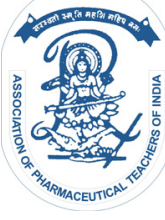

www.ijper.org 
services to residents. ${ }^{3,4}$ Most residents in these areas of Korea are 65 years old or older. ${ }^{5}$ Therefore, it is highly likely that although many residents suffer from chronic diseases (CDs) such as hypertension and diabetes mellitus, they cannot receive health services in a timely manner. This may lead to the aggravation of many CDs and conditions that could be managed well with simple medical interventions. In addition, due to the shortage of health care facilities in these areas, the residents do not have sufficient opportunities to receive education about medications, which may contribute to patients' poor awareness of their medications. Gray and colleagues reported that patients' poor awareness of their current medications could result in a low compliance rate. ${ }^{6}$

A club at Chosun University College of Pharmacy (CUCP) in Korea has voluntarily provided health care for medically underserved residents in the rural areas of South Jeolla Province in Korea every year. The volunteer team usually consists of faculty members, licensed pharmacists, and pharmacy students who volunteer for about 3 days during the summer vacation. The pharmacists in this team play an important role in prescribing and dispensing medications because the health care systems in the regions where they volunteer are not regulated by the KHCSRA 2000. They also serve as team leaders as well as instructors of pharmacy students participating in the voluntary activities. This team provides not only valuable patient consultations regarding health and medications but also urine dipstick tests and blood glucose tests during their voluntary activities.

Some US pharmacy schools have tried to include a medical mission as an advanced pharmacy practice experience (APPE) or an elective course in their pharmacy curricula. $^{7-9}$ The students who participated in the medical mission APPE reported that this type of APPE provided the opportunities regarding interdisciplinary education, cultural competence, and patient-focused care which should be addressed in APPE. ${ }^{8}$ Some studies have also introduced how to prepare a pharmacy-led medical mission trip. ${ }^{10,11}$ In addition, Brown and colleagues reported in an exploratory study that it was likely that participation in a medical mission trip would positively affect some of the beliefs and perceptions of pharmacy students. ${ }^{12}$ However, the voluntary activities of pharmacy students have been rarely performed and studied in Korea.

The primary objective of this study was to introduce the voluntary activities that pharmacists and pharmacy students perform in regions of Korea where drug prescribing has not yet been separated from dispensing. The secondary objective was to use a survey to examine and analyse health conditions, and the prevalence and management of CDs, in the residents of these regions.

\section{MATERIALS AND METHODS}

The voluntary activities took place in Hampyeong-gun (HG) and Gurye-gun (GG) of South Jeolla Province. These voluntary activities were planned as 3-month projects that included team formation, formulary development and medication acquisition, site selection, and 3-day voluntary services.

The volunteer teams were formed by faculty members, CUCP alumni, and pharmacy students. The alumni voluntarily participated in the teams after they received participation requests from the pharmacy students. Formulary development started as early as possible in order to acquire sufficient medications and supplies within the fixed time frame. The medication formulary was established by considering the characteristics of residents, the disease prevalence rates at the voluntary service sites, and the medication formulary used in the previous year. Once the appropriate medication formulary was established, official letters enquiring about medication donations were sent out to pharmaceutical companies, and the alumni were asked to donate the necessary medications that would not be received from the companies. The medically underserved regions that did not separate prescribing from dispensing were selected for the voluntary services because the pharmacists directly prescribed medications to patients during the voluntary service days.

A temporary pharmacy was set up at a conveniently accessible place for patients on a daily basis. Service hours were approximately 8 hours long; however, the time varied between the service days due to the difference in the number of patients visiting the pharmacy each day. The pharmacy was divided into four separate sections: reception, external injury, internal injury, and consultation. The pharmacy students obtained the patients' information including blood pressure, blood glucose level, and the urine dipstick test at the reception desk. If the patients had dermatologic diseases, they were sent to the external injury section. Otherwise, the patients were sent to the internal injury section and saw the pharmacists. After asking the patients detailed questions about their conditions, the pharmacists prescribed medications, and the pharmacy students filled and dispensed prescriptions with brief consultations. The pharmacy students implemented all of their work under the supervision of the pharmacists during all of the service days. 
The pharmacy students collected data using a selfreported questionnaire after thoroughly explaining the objective of the study to the patients who visited the temporary pharmacy during the voluntary services. The survey was anonymously administered before or after they saw the pharmacists. Completion of the survey was the means of consent. The questionnaire consisted of 23 questions classified into four categories: 4 demographic questions, 4 questions regarding the resident's health conditions, 11 questions regarding the prevalence of CDs, and 4 questions regarding the management of the CDs. The institutional review board of Chosun University reviewed and approved the research study.

The responses were coded and transferred into SPSS for Windows, version 20.0 (SPSS Inc., Chicago, US). Continuous variables were presented as means $( \pm S D)$, and categorical variables were presented as frequencies (n) and percentages (\%). T-tests and Chi-square tests were used to compare the differences in means and proportions, respectively. The a-priori level of the $p$-value was set at $p<0.05$ and missing data were not estimated or included in the analysis.

\section{RESULTS}

A total of 352 residents completed the survey. One hundred and fifteen residents (32.7\%) were male, and 237 $(67.3 \%)$ were female; however, there was no significant difference in sex ratios between HG and GG $(p=0.053)$. The majority of residents $(66.3 \%)$ were over 70 years old, and the mean ages of HG and GG were $70.80 \pm 11.64$ and $72.63 \pm 10.22$ years, respectively $(t=-1.479, d f=349$, $p=0.140)$. The majority of residents $(65.7 \%)$ were engaged mainly in agriculture. The complete demographic characteristics of the surveyed residents are provided in Table 1.

Forty-three residents $(12.5 \%)$ responded that their health conditions were good. Approximately $44 \%$ of residents reported that they had received treatments on time if necessary, and residents in HG were more likely to receive treatment on time than those in GG $(p<0.001)$. The majority of residents $(72.5 \%)$ took at least one medication on a regular basis. In addition, $8.2 \%$ of residents responded that they had experienced adverse drug effects after taking medications. The complete list of residents' health conditions is presented in Table 2.

Approximately $77 \%$ of residents had at least one CD. The majority of CDs included hypertension (49.9\%), arthritis $(44.8 \%)$, muscle pain $(24.1 \%)$, gastrointestinal disorder $(20.9 \%)$, diabetes mellitus $(20.6 \%)$, and osteo- porosis $(20.5 \%)$. Table 3 presents the prevalence of the CDs found by the survey.

About $73 \%$ of the surveyed residents responded that they took all doses of the prescribed medications whereas a small proportion of residents $(5.7 \%)$ were found to miss all of them. Residents in HG were more likely to take all doses of the prescribed medications than those in GG $(p<0.001)$. The surveyed residents' medication non-compliance was due to forgetting to take medications (33.7\%), followed by the inconvenient locations of hospitals and pharmacies (23.7\%). Residents in HG were more likely to forget taking medications than those in GG $(p<0.001)$. It was also found that most of the residents $(96.3 \%)$ surveyed had received at least minimal information and education about the medications at a hospital, pharmacy or public health centre. Only $6.5 \%$ of surveyed residents were unsatisfied with the information and education provided about the medications at a hospital, pharmacy or public health centre. The detailed survey results for the management of the CDs are provided in Table 4.

\section{DISCUSSION}

This study introduced the voluntary activities of pharmacists and pharmacy students in the regions of Korea where dispensing is not separate from regular medical practice. It also surveyed and analysed the health conditions, and prevalence and management of CDs, of the residents of these regions. To our knowledge, it is the first report about the voluntary activities of pharmacy students in medically underserved areas of Korea.

During the two 3-day voluntary activity projects in the medically underserved areas of Korea that do not have separate prescribing and dispensing, the pharmacy students dispensed and compounded medications under the supervision of licensed pharmacists. The pharmacy students also provided consultations about medications for patients. Some studies have reported that participation in a medical mission provides pharmacy students with rare opportunities that they could not experience before graduation, such as a better understanding of health care disparities, pharmacy workflow, formulary management, interdisciplinary team work, counselling patients, and making clinical decisions. ${ }^{7,8}$ However, this study could not report whether the pharmacy students obtained these opportunities through participation in the voluntary activities; hence, this point should be addressed in future studies.

According to a study by Clements and colleagues, most members in an interdisciplinary team strongly agreed that the role of pharmacists is important for providing 


\begin{tabular}{|c|c|c|c|c|}
\hline \multirow{2}{*}{ Characteristic } & \multicolumn{4}{|c|}{ N (\%) } \\
\hline & Total & Hampyeong-gun & Gurye-gun & p-valuea \\
\hline \multicolumn{5}{|c|}{ Sex } \\
\hline Male & $115 / 352(32.7)$ & $65 / 224(29.0)$ & $50 / 128(39.1)$ & \multirow{2}{*}{0.053} \\
\hline Female & 237/352 (67.3) & $159 / 224(71.0)$ & $78 / 128(60.9)$ & \\
\hline \multicolumn{5}{|c|}{ Age (y) } \\
\hline$<50$ & $14 / 351(4.0)$ & $11 / 223(4.9)$ & $3 / 128(2.3)$ & \multirow{5}{*}{0.331} \\
\hline $50-59$ & $37 / 351$ (10.5) & $28 / 223(12.6)$ & $9 / 128(7.0)$ & \\
\hline $60-69$ & 67/351 (19.1) & $41 / 223(18.4)$ & $26 / 128(20.3)$ & \\
\hline $70-79$ & $156 / 351(44.4)$ & $94 / 223(42.2)$ & $62 / 128(48.4)$ & \\
\hline$\geq 80$ & 77/351 (21.9) & $49 / 223(22.0)$ & 28/128 (21.9) & \\
\hline Mean ( \pm SD) & $71.46( \pm 11.16)$ & $70.80( \pm 11.64)$ & $72.63( \pm 10.22)$ & $0.140^{\mathrm{b}}$ \\
\hline \multicolumn{5}{|c|}{ Business } \\
\hline Agriculture & $216 / 329(65.7)$ & $127 / 203(62.6)$ & $89 / 126(70.6)$ & \multirow{6}{*}{0.023} \\
\hline Livestock raising & $1 / 329(0.3)$ & $0 / 203(0.0)$ & $1 / 126(0.8)$ & \\
\hline Fishery & $1 / 329(0.3)$ & $0 / 203(0.0)$ & $1 / 126(0.8)$ & \\
\hline Service & 6/329 (1.8) & $2 / 203(1.0)$ & 4/126 (3.2) & \\
\hline Unemployed & $96 / 329(29.2)$ & $65 / 203(32.0)$ & $31 / 126(24.6)$ & \\
\hline Others & $9 / 329(2.7)$ & $9 / 203(4.4)$ & $0 / 126(0.0)$ & \\
\hline \multicolumn{5}{|c|}{ Type of health security program } \\
\hline $\begin{array}{l}\text { National health insurance } \\
\text { program }\end{array}$ & $228 / 252(90.5)$ & 110/124 (88.7) & $118 / 128(92.2)$ & \multirow{4}{*}{$<0.001$} \\
\hline Type 1 medical aid program & $8 / 252(3.2)$ & $0 / 124(0.0)$ & $8 / 128(6.3)$ & \\
\hline Type 2 medical aid program & $3 / 252(1.2)$ & $1 / 124(0.8)$ & $2 / 128(1.6)$ & \\
\hline None & $13 / 252(5.2)$ & $13 / 124(10.5)$ & $0 / 128(0.0)$ & \\
\hline
\end{tabular}

aderived from chi-square Test.

bderived from T-test.

\begin{tabular}{|c|c|c|c|c|}
\hline \multirow{2}{*}{ Characteristic } & \multicolumn{4}{|c|}{$\mathrm{N}(\%)$} \\
\hline & Total & Hampyeong-gun & Gurye-gun & p-value ${ }^{a}$ \\
\hline \multicolumn{5}{|c|}{ Current health status } \\
\hline Good & $43 / 344(12.5)$ & 28/216 (13.0) & $15 / 128(11.7)$ & \multirow{3}{*}{0.881} \\
\hline Normal & $132 / 344(38.4)$ & $84 / 216(38.9)$ & $48 / 128(37.5)$ & \\
\hline Bad & $169 / 344(49.1)$ & $104 / 216(48.1)$ & $65 / 128(50.8)$ & \\
\hline \multicolumn{5}{|c|}{ Reasons for non-treatment or treatment delay } \\
\hline Mild symptom & $52 / 261(19.9)$ & $19 / 133(14.3)$ & $33 / 128(25.8)$ & \multirow{5}{*}{$<0.001$} \\
\hline Financial problem & $18 / 261(6.9)$ & $11 / 133(8.3)$ & $7 / 128(5.5)$ & \\
\hline $\begin{array}{l}\text { Inconvenient location of } \\
\text { medical facility }\end{array}$ & $31 / 261(11.9)$ & $16 / 133(12.0)$ & $15 / 128(11.7)$ & \\
\hline Health problem & $46 / 261(17.6)$ & 9/133 (6.8) & $37 / 128(28.9)$ & \\
\hline No experience & $114 / 216(43.7)$ & $78 / 133(58.6)$ & $36 / 128(28.1)$ & \\
\hline \multicolumn{5}{|c|}{ No. of medications taken on a regular basis } \\
\hline 0 & $96 / 349(27.5)$ & $71 / 223(31.8)$ & 25/126 (19.8) & \multirow{4}{*}{0.112} \\
\hline $1-2$ & $164 / 349(47.0)$ & $97 / 223(43.5)$ & $67 / 126(53.2)$ & \\
\hline $3-4$ & $71 / 349(20.3)$ & $44 / 223(19.7)$ & $27 / 126(21.4)$ & \\
\hline$\geq 5$ & $18 / 349(5.2)$ & $11 / 223(4.9)$ & $7 / 126(5.6)$ & \\
\hline $\begin{array}{c}\text { Experiences of adverse } \\
\text { drug effects }\end{array}$ & $28 / 343(8.2)$ & $14 / 216(6.5)$ & $14 / 127(11.0)$ & $<0.001$ \\
\hline
\end{tabular}

aderived from chi-square test. 


\begin{tabular}{|c|c|c|c|c|}
\hline \multirow{2}{*}{ Characteristic } & \multicolumn{4}{|c|}{ N (\%) } \\
\hline & Total & Hampyeong-gun & Gurye-gun & p-value ${ }^{a}$ \\
\hline \multicolumn{5}{|c|}{ Chronic disease } \\
\hline Yes & $263 / 344(76.5)$ & $156 / 218(71.6)$ & $107 / 126(84.9)$ & \multirow{2}{*}{0.005} \\
\hline No & $81 / 344(23.5)$ & $62 / 218(28.4)$ & $19 / 126(15.1)$ & \\
\hline \multicolumn{5}{|c|}{ Hypertension } \\
\hline Yes & 175/351 (49.9) & $111 / 224(49.6)$ & $64 / 127(50.4)$ & 0.424 \\
\hline Medication & $167 / 345(48.4)$ & $109 / 221(49.3)$ & $58 / 124(46.8)$ & 0.158 \\
\hline \multicolumn{5}{|c|}{ Diabetes Mellitus } \\
\hline Yes & $72 / 350(20.6)$ & $37 / 224(16.5)$ & $35 / 126(27.8)$ & 0.042 \\
\hline Medication & $70 / 340(20.6)$ & $35 / 221(15.8)$ & $35 / 119(29.4)$ & 0.004 \\
\hline \multicolumn{5}{|c|}{ Hyperlipidemia } \\
\hline Yes & $31 / 346(9.0)$ & $8 / 219(3.7)$ & 23/127 (18.1) & $<0.001$ \\
\hline Medication & $23 / 335(6.9)$ & $4 / 217(1.8)$ & $19 / 118(16.1)$ & $<0.001$ \\
\hline \multicolumn{5}{|c|}{ Osteoporosis } \\
\hline Yes & $72 / 351(20.5)$ & $38 / 224(17.0)$ & $34 / 127(26.8)$ & 0.087 \\
\hline Medication & $48 / 340(14.1)$ & $22 / 219(10.0)$ & 26/121 (21.5) & 0.007 \\
\hline \multicolumn{5}{|c|}{ Asthma } \\
\hline Yes & $11 / 347(3.2)$ & $7 / 222(3.2)$ & $4 / 125(3.2)$ & 0.995 \\
\hline Medication & 6/336 (1.8) & $4 / 222(1.8)$ & $2 / 114(1.8)$ & 0.772 \\
\hline \multicolumn{5}{|c|}{ Parkinson's Disease } \\
\hline Yes & $3 / 347(0.9)$ & $3 / 223(1.3)$ & $0 / 124(0.0)$ & 0.005 \\
\hline Medication & $3 / 336(0.9)$ & $3 / 223(1.3)$ & $0 / 113(0.0)$ & 0.174 \\
\hline \multicolumn{5}{|c|}{ Cardiac Disorder } \\
\hline Yes & $31 / 346(9.0)$ & $20 / 224(8.9)$ & $11 / 122(9.0)$ & 0.519 \\
\hline Medication & $26 / 336(7.7)$ & $16 / 222(7.2)$ & $10 / 114(8.8)$ & 0.327 \\
\hline \multicolumn{5}{|c|}{ Gastrointestinal Disorder } \\
\hline Yes & $72 / 345(20.9)$ & $39 / 222(17.6)$ & $33 / 123(26.8)$ & 0.027 \\
\hline Medication & $30 / 339(8.8)$ & $17 / 220(7.7)$ & $13 / 119(10.9)$ & 0.590 \\
\hline \multicolumn{5}{|c|}{ Arthritis } \\
\hline Yes & $154 / 344(44.8)$ & 89/223 (39.9) & 65/121 (53.7) & 0.005 \\
\hline Medication & $68 / 338(20.1)$ & $43 / 221(19.5)$ & $25 / 117(21.4)$ & 0.002 \\
\hline \multicolumn{5}{|c|}{ Muscle Pain } \\
\hline Yes & $82 / 340(24.1)$ & $44 / 219(20.1)$ & 38/121 (31.4) & 0.020 \\
\hline Medication & $24 / 334(7.2)$ & $8 / 216(3.7)$ & $16 / 118(13.6)$ & 0.002 \\
\hline
\end{tabular}

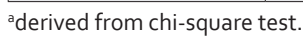

medication knowledge and proper pharmacotherapy management. ${ }^{13}$ One study also reported that a pharmacy student participating in a medical mission experienced a positive change in medical students' attitudes to the pharmacy students. ${ }^{7}$ Based on these studies' results, it is likely that involving pharmacists and pharmacy students in an interdisciplinary team for voluntary work may be helpful for positively changing other health professionals' perceptions and attitudes toward the role of the pharmacist in Korea. However, it is not likely that the pharmacy students could experience interdisciplinary teamwork because the volunteer teams were composed of only pharmacists and pharmacy students. Thus, collaboration with other health professionals at university may be necessary in order to build an interdisciplinary team for voluntary work in the near future.

In Korea, new pharmacy schools were founded to accommodate more students during the transitional period of the Korean pharmacy educational system from 4 years to 6 years, and the final year of pharmacy school usually consists of internship programmes in various settings. In South Jeolla Province, where CUCP 


\begin{tabular}{|c|c|c|c|c|}
\hline \multirow[b]{2}{*}{ Characteristic } & \multicolumn{4}{|c|}{$\mathbf{N}(\%)$} \\
\hline & Total & $\begin{array}{c}\text { Hampyeong- } \\
\text { gun }\end{array}$ & Gurye-gun & p-valuea \\
\hline \multicolumn{5}{|c|}{ Medication Compliance in Chronic Diseases } \\
\hline All doses taken/week & $\begin{array}{c}207 / 283 \\
(73.1)\end{array}$ & $\begin{array}{c}143 / 169 \\
(84.6)\end{array}$ & $\begin{array}{l}64 / 114 \\
(56.1)\end{array}$ & \multirow{6}{*}{$<0.001$} \\
\hline 1-2 doses missed/week & $\begin{array}{c}38 / 283 \\
(13.4)\end{array}$ & $\begin{array}{c}13 / 169 \\
(7.7)\end{array}$ & $\begin{array}{l}25 / 114 \\
(21.9)\end{array}$ & \\
\hline 3-4 doses missed/week & $\begin{array}{c}10 / 283 \\
(3.5)\end{array}$ & $\begin{array}{c}2 / 169 \\
(1.2)\end{array}$ & $\begin{array}{r}8 / 114 \\
(7.0)\end{array}$ & \\
\hline 3-4 days taken/week & $\begin{array}{c}4 / 283 \\
(1.4)\end{array}$ & $\begin{array}{c}2 / 169 \\
(1.2)\end{array}$ & $\begin{array}{l}2 / 114 \\
(1.8)\end{array}$ & \\
\hline 1-2 days taken/week & $\begin{array}{c}8 / 283 \\
(2.8)\end{array}$ & $\begin{array}{l}1 / 169 \\
(0.6)\end{array}$ & $\begin{array}{c}7 / 114 \\
(6.1)\end{array}$ & \\
\hline All doses missed/week & $\begin{array}{c}16 / 283 \\
(5.7)\end{array}$ & $\begin{array}{c}8 / 169 \\
(4.7)\end{array}$ & $\begin{array}{r}8 / 114 \\
(7.0)\end{array}$ & \\
\hline \multicolumn{5}{|c|}{ Reasons for Medication Non-compliance } \\
\hline Inconvenient locations of hospital and pharmacy & $\begin{array}{c}40 / 169 \\
(23.7)\end{array}$ & $\begin{array}{l}22 / 70 \\
(31.4)\end{array}$ & $\begin{array}{l}18 / 99 \\
(18.2)\end{array}$ & \multirow{6}{*}{$<0.001$} \\
\hline High hospital costs & $\begin{array}{c}16 / 169 \\
(9.5)\end{array}$ & $\begin{array}{l}7 / 70 \\
(10.0)\end{array}$ & $\begin{array}{l}9 / 99 \\
(9.1)\end{array}$ & \\
\hline Taking medications as needed for symptoms & $\begin{array}{c}20 / 169 \\
(11.8)\end{array}$ & $\begin{array}{l}2 / 70 \\
(2.9)\end{array}$ & $\begin{array}{l}18 / 99 \\
(18.2)\end{array}$ & \\
\hline Discontinuing medications due to no improvement of symptoms & $\begin{array}{c}20 / 169 \\
(11.8)\end{array}$ & $\begin{array}{l}2 / 70 \\
(2.9)\end{array}$ & $\begin{array}{l}18 / 99 \\
(18.2)\end{array}$ & \\
\hline Experiences of drug adverse effects such as heartburn & $\begin{array}{c}16 / 169 \\
(9.5)\end{array}$ & $\begin{array}{l}5 / 70 \\
(7.1)\end{array}$ & $\begin{array}{l}11 / 99 \\
(11.1)\end{array}$ & \\
\hline Forgetting taking medications & $\begin{array}{c}57 / 169 \\
(33.7)\end{array}$ & $\begin{array}{l}32 / 70 \\
(45.7)\end{array}$ & $\begin{array}{l}25 / 99 \\
(25.3)\end{array}$ & \\
\hline \multicolumn{5}{|c|}{ Degree of providing education and information about medications at a hospital, pharmacy or public health centre } \\
\hline $\begin{array}{l}\text { I had received enough information and education about each } \\
\text { medication }\end{array}$ & $\begin{array}{c}55 / 294 \\
(18.7)\end{array}$ & $\begin{array}{c}26 / 176 \\
(14.8)\end{array}$ & $\begin{array}{l}29 / 118 \\
(24.6)\end{array}$ & \multirow{4}{*}{0.181} \\
\hline I had received information and education about some medications & $\begin{array}{c}130 / 294 \\
(44.2)\end{array}$ & $\begin{array}{l}81 / 176 \\
(46.0)\end{array}$ & $\begin{array}{c}49 / 118 \\
(41.5)\end{array}$ & \\
\hline $\begin{array}{l}\text { I had received minimal information and education about medications } \\
\text { (e.g. Take a medication three times a day } 30 \text { mins after a meal) }\end{array}$ & $\begin{array}{c}98 / 294 \\
(33.3)\end{array}$ & $\begin{array}{l}63 / 176 \\
(35.8)\end{array}$ & $\begin{array}{l}35 / 118 \\
(29.7)\end{array}$ & \\
\hline $\begin{array}{l}\text { I had never received any information and education about } \\
\text { medications }\end{array}$ & $\begin{array}{c}11 / 294 \\
(3.7)\end{array}$ & $\begin{array}{l}6 / 176 \\
(3.4)\end{array}$ & $\begin{array}{l}5 / 118 \\
(4.2)\end{array}$ & \\
\hline \multicolumn{5}{|c|}{ Satisfaction with information and education about medications at a hospital, pharmacy or public health centre } \\
\hline Satisfied & $\begin{array}{c}108 / 294 \\
(36.7)\end{array}$ & $\begin{array}{c}73 / 175 \\
(41.7)\end{array}$ & $\begin{array}{l}35 / 119 \\
(29.4)\end{array}$ & \multirow{3}{*}{0.003} \\
\hline Neutral & $\begin{array}{c}167 / 294 \\
(56.8)\end{array}$ & $\begin{array}{c}97 / 175 \\
(55.4)\end{array}$ & $\begin{array}{c}70 / 119 \\
(58.8)\end{array}$ & \\
\hline Unsatisfied & $\begin{array}{c}19 / 294 \\
(6.5)\end{array}$ & $\begin{array}{c}5 / 175 \\
(2.9)\end{array}$ & $\begin{array}{l}14 / 119 \\
(11.8)\end{array}$ & \\
\hline
\end{tabular}

aderived from chi-square test.

is located, three other pharmacy schools have to share limited rotation sites. Therefore, it is crucial to develop sufficient and various rotation sites to accommodate all pharmacy students from the four schools. One possible solution to this issue may be to develop and implement an elective course as an advanced pharmacy practice experience rotation in the medically underserved areas in South Jeolla Province. Through involvement in this kind of course, the pharmacy students can not only experience triaging patients, compounding and dispensing medications, and providing patient counselling but can also be exposed to direct patient care. ${ }^{9}$ In addition, they can be expected to improve their communication skills with elderly people because most residents from the 
medically underserved areas in Korea are over 65 years old. ${ }^{5}$

The mean age of the respondents to the survey was approximately 71 years old, and the majority of respondents answered that they were taking at least one medication on a regular basis. Therefore, although this study found that the medication compliance rate of residents surveyed at HG and GG was high, it is expected that those of other rural areas in South Jeolla Province may be low owing to the elderly people's decreased memory and understanding. This is supported by the result that one-third of respondents answered that the reason for medication non-compliance was forgetting to take the medications. In addition, Gray and colleagues reported that low medication compliance was related to poor cognition and the number of medications. ${ }^{6}$ Thus, it may be important to offer enough patient counselling and education about medications, which the elderly people receive both verbally and in written form. This work could be implemented by the pharmacy students during their voluntary activities.

This study showed that approximately $73 \%$ of respondents suffered from at least one $\mathrm{CD}$. In particular, the occurrence of CDs related to the musculoskeletal system, such as arthritis and muscle pain, was high relative to other CDs. This difference may be related to the finding that the majority of respondents were elderly people who engaged mainly in physical work, such as agriculture. A similar result was found in a previous study conducted with rural residents in Korea in which ailments of the musculoskeletal system were the most prevalent health problem. ${ }^{14}$ Thus, this point should be considered in formulary development. Additionally, to manage CDs effectively in rural areas, it may be helpful to encourage pharmacy students to participate in offering health promotion and disease prevention services during the voluntary activities.

This study has a few limitations that should be mentioned. The survey was conducted with residents from only one province, which makes it difficult to generalise the survey results to other provinces. Furthermore, this study could not indicate if the pharmacy students received beneficial opportunities by participating in the voluntary activities. This point will have to be addressed in a future study. Additionally, because the volunteer teams were composed of only pharmacists and pharmacy students, they did not have an important opportunity to collaborate with other health care professionals. Consequently, this study could not report other professionals' satisfaction with the pharmacy services during the voluntary activities.

\section{CONCLUSION}

This study is the first to provide insight into Korean pharmacy students' voluntary activities in medically underserved areas that do not have the separation of prescribing and dispensing medications. The voluntary activities of pharmacists and pharmacy students can be valuable for providing medical care in order to manage CDs effectively in medically underserved areas in Korea.

\section{ACKNOWLEDGEMENT}

This work was supported by the National Research Foundation of Korea (NRF) grant funded by the Korea government (MSIP) (No. 2016R1C1B1015938).

\section{CONFLICTS OF INTEREST}

There is no conflict of interest for the present communication.

\section{ABBREVIATION USED}

KHCSRA 2000: Korean Health Care System Reform Act of 2000; CD: chronic disease; CUCP: Chosun University College of Pharmacy; APPE: advanced pharmacy practice experience; HG: Hampyeong-gun; GG: Gurye-gun.

\section{REFERENCES}

1. Kim HJ and Ruger JP. Pharmaceutical reform in South Korea and the lessons it provides. Health Affairs. 2008;27(4):w260-9. http://dx.doi.org/10.1377/ hlthaff.27.4.w260; PMid:18508813.

2. Kwon S. Pharmaceutical reform and physician strikes in Korea: separation of drug prescribing and dispensing. Social Science \& Medicine. 2003;57(3):529-38. http://dx.doi.org/10.1016/S0277-9536(02)00378-7

3. Korean Ministry of Health \& Welfare. Available from http://www.mw.go.kr. Accessed on November 14, 2014.

4. The Korea Institute for Health and Social Affairs. Available from https://www. kihasa.re.kr. Accessed on November 14, 2014.

5. Statistics Korea. Available from http://kostat.go.kr/portal/korea/index.action. Accessed on November 14, 2014.

6. Gray SL, Mahoney JE and Blough DK. Medication adherence in elderly patients receiving home health services following hospital discharge. Ann Pharmacother. 2001;35(5):539-45. http://dx.doi.org/10.1345/aph.10295 ; PMid:11346058.

7. Ward CT, Nemire RE and Daniel KP. The development and assessment of a medical mission elective course. Am J Pharm Educ. 2005;69(3):330-8. http:// dx.doi.org/10.5688/aj690350.

8. WerremeyerAB and Skoy ET. A medical mission to Guatemala as an advanced pharmacy practice experience. Am J Pharm Educ. 2012;76(8):1-8. http:// dx.doi.org/10.5688/ajpe768156 ; PMid:23129855 PMCid:PMC3475785.

9. Brown DA and Ferrill MJ. Planning a pharmacy-led medical mission trip, part 3: development and implementation of an elective medical missions advanced pharmacy practice experience (APPE) rotation. Ann Pharmacother. 2012;46:1111-4. http://dx.doi.org/10.1345/aph.1Q784 : http:// dx.doi.org/10.1345/aph.1Q735; PMid:22739719.

10. Brown DA and Ferrill MJ. Planning a pharmacy-led medical mission trip, part 1: focus on medication acquisition. Ann Pharmacother. 2012;46:751-9. http:// 
dx.doi.org/10.1345/aph.1Q784 http://dx.doi.org/10.1345/aph.1Q53 http:// dx.doi.org/10.1345/aph.1Q547.

11. Brown DA, Brown DL and Yocum CK. Planning a pharmacy-led medical mission trip, part 2: servant leadership and team dynamics. Ann Pharmacother. 2012;46:895-900. http://dx.doi.org/10.1345/aph.1Q54; PMid:22619473.

12. Brown DA, Fairclough JL and Ferrill MJ. Planning a pharmacy-led medical mission trip, part 4: an exploratory study of student experiences. Ann Pharmacother. 2012;46:1250-5. http://dx.doi.org/10.1345/aph.1Q78; PMid:22892269.
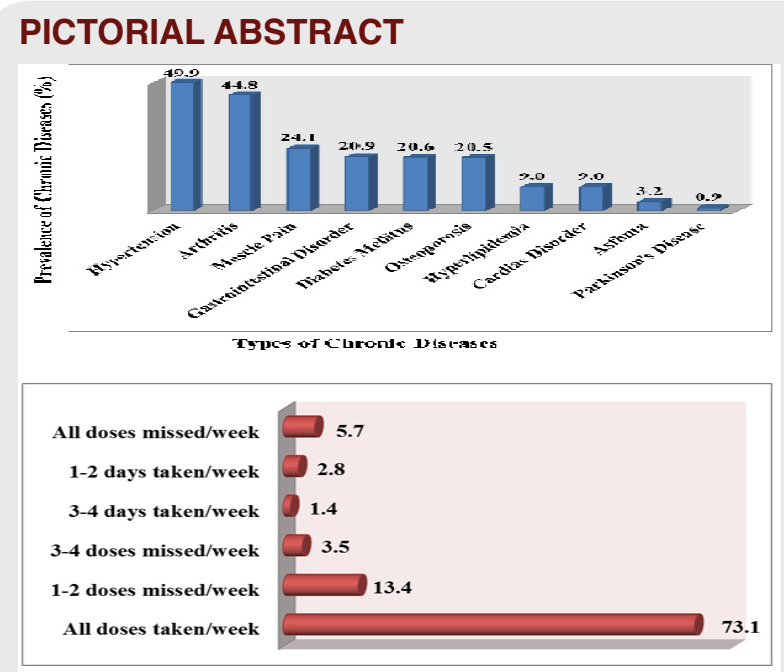

Medication Compliance in Chronic Diseases
13. Clements JN, Rager ML and Vescovi EM. The value of pharmacy services on a short-term medical mission trip: description of services and assessment of team satisfaction. Ann Pharmacother 2011;45(12):1576-81. http://dx.doi. org/10.1345/aph.1Q32 ; PMid:22068242

14. Park JS, Kwon SM and Oh YJ. Health promotion behavior, health problems, perceived health status and farmers' syndrome of rural residents. J Agri Med \& Community Health 2009;34(1):47-57. http://dx.doi.org/10.5393/ JAMCH.2009.34.1.047

\section{SUMMARY}

- About $66 \%$ of residents were over 70 years old. More than $12 \%$ of residents reported that their health conditions were good, and about $76 \%$ of residents had at least one chronic disease.

- Over $73 \%$ of residents responded that they took all doses of medications as prescribed while $5.7 \%$ of residents reported that they missed all those of them.

- Through the volunteer activities, pharmacists and pharmacy students will play a meaningful role in providing a medical care in order to effectively manage CDs at the medically underserved areas in Korea. 